\title{
Weaning Outcomes and 28-day Mortality after Tracheostomy in COVID-19 Patients in Central India: A Retrospective Observational Cohort Study
}

Sunaina Tejpal Karna ${ }^{1} \odot$, Saurabh Trivedi ${ }^{2} \odot$, Pooja Singh ${ }^{3} \odot$, Alkesh Khurana ${ }^{4} \odot$, Revadi Gouroumourty ${ }^{5}$, Brahmam Dodda $^{6} \odot$, Saurabh Saigal ${ }^{7} \odot$, Jai Prakash Sharma ${ }^{8} \odot$, Amit Karna ${ }^{9} \odot$, Pranav Shrivastava ${ }^{10} \odot$, Aqeel Hussain ${ }^{11} \odot$, Vikas Gupta ${ }^{12} \odot$, Gankalyan Behera $^{13} \odot$, Vaishali Waindeskar ${ }^{14} \odot$

\begin{abstract}
Background: Tracheostomy is integral in long-term intensive care of coronavirus disease-2019 (COVID-19) patients. There is a paucity of studies on weaning outcomes and mortality after tracheostomy in COVID-19 in Indian scenario.

Materials and methods: We conducted a retrospective, single-center, observational study of severe COVID-19 patients who underwent elective tracheostomy $(n=65)$ during critical care in a tertiary care institute in Central India from May 1, 2020, to April 30, 2021. Data were collected from Medical records, ICU charts, and follow-up visits by patient. A primary objective was to study the clinical characteristics, tracheostomy complications, weaning outcomes, and mortality at 28 and 60 days of ICU admission. We categorized the cohort into two groups (deceased and survivor) and studied association of clinical parameters with 28-day mortality. Cox Proportional regression analysis was applied to calculate the hazard ratio among the predictors of mortality with $p$ value $<0.05$ as significant.

Results: Elective tracheostomy was done in 69 of $436(15.8 \%)$ patients on invasive mechanical ventilation, of which 65 were included. Tracheostomy was percutaneous in 45/65 (69\%) and surgical in 20/65 (31\%) with timing from intubation as early in 41/65 and late in 24/65 with most common indication as weaning failure followed by anticipated prolonged ventilation. Tracheostomy complications were present in $29 / 65$ (45\%) patients with no difference in complication rates between timing and type of tracheostomy. Downsizing, decannulation, and weaning were successful in $22 \%, 32$ (49\%), and 35/65 (54\%) patients after tracheostomy. The 28-day mortality was 30/65 (46\%). The fractional inspired oxygen concentration $\left(\mathrm{FiO}_{2}\right)$ requirement in survivors was lower $(0.4-0.6, p=0.015)$ with a higher $\mathrm{PaO}_{2} / \mathrm{FiO}_{2}$ ratio $(118-200, p=0.033)$. Early tracheostomy within 7 days of intubation was not associated with weaning or survival benefit.

Conclusions: We suggest that tracheostomy should be delayed to after 7 days of intubation, especially till $\mathrm{FiO}_{2}$ reduces to 0.5 with improvement in $\mathrm{PaO}_{2} / \mathrm{FiO}_{2}$ for better outcomes and avoiding a wasted procedure (CTRI/2021/07/034768).

Study Highlights: Tracheostomy is integral in care of COVID-19 patients needing prolonged ventilation. There is no difference in complications in early/late or percutaneous dilatational/surgical technique. We observed successful weaning post-tracheostomy in $54 \%$ patients. Mortality at 28 days was $46 \%$. Early tracheostomy within 7 days of intubation did not improve weaning or survival.

Keywords: COVID-19 patients, Intensive care, Mortality, Tracheostomy, Weaning success.

Indian Journal of Critical Care Medicine (2022): 10.5005/jp-journals-10071-24080
\end{abstract}

\section{INTRODUCTION}

Tracheostomy is a standard of care in patients on invasive mechanical ventilation in coronavirus disease-2019 (COVID-19). ${ }^{1-3}$ Despite some guidelines and case series published, evidence on weaning and mortality after elective Tracheostomy in critical COVID-19 patients on mechanical ventilation from India is scarce. ${ }^{4-7}$

With this research gap, this retrospective, observational study was done with a primary objective of study of tracheostomy complications, weaning outcomes, and 28-day mortality in tracheostomized COVID-19 patients. Our secondary objective was to study association of weaning outcomes with timing of tracheostomy after intubation, and to find predictors of mortality at 28 days of ICU admission.

\section{Materials and Methods}

\section{Study Design and Subjects}

This retrospective, single-center, observational cohort study was conducted in the intensive care unit (ICU) of a tertiary care
1-3,6-8,10,14 Department of Anesthesiology and Critical Care, All India Institute of Medical Sciences, Bhopal, Madhya Pradesh, India

${ }^{4,11}$ Department of Pulmonary Medicine, All India Institute of Medical Sciences, Bhopal, Madhya Pradesh, India

${ }^{5}$ Department of Community and Family Medicine, All India Institute of Medical Sciences, Bhopal, Madhya Pradesh, India

${ }^{9}$ Department of Anesthesiology and Critical Care, Chirayu Medical College and Hospital, Bhopal, Madhya Pradesh, India

${ }^{12,13}$ Department of Otorhinolaryngology, Head and Neck Surgery, All India Institute of Medical Sciences, Bhopal, Madhya Pradesh, India

Corresponding Author: Pooja Singh, Department of Anesthesiology and Critical Care, All India Institute of Medical Sciences, Bhopal, Madhya Pradesh, India, Phone: +91 9340969292, e-mail: pooja.anesth@aiimsbhopal.edu.in

How to cite this article: Karna ST, Trivedi S, Singh P, Khurana A, Gouroumourty R, Dodda B, et al. Weaning Outcomes and 28-day Mortality after Tracheostomy in COVID-19 Patients in Central India: A Retrospective Observational Cohort Study. Indian J Crit Care Med 2022;26(1):85-93.

(O) The Author(s). 2022 Open Access This article is distributed under the terms of the Creative Commons Attribution 4.0 International License (https://creativecommons. org/licenses/by-nc/4.0/), which permits unrestricted use, distribution, and non-commercial reproduction in any medium, provided you give appropriate credit to the original author(s) and the source, provide a link to the Creative Commons license, and indicate if changes were made. The Creative Commons Public Domain Dedication waiver (http://creativecommons.org/publicdomain/zero/1.0/) applies to the data made available in this article, unless otherwise stated. 
institute in Central India including COVID-19 patients electively tracheostomized during intensive care from May 1, 2020, to April 30, 2021. Ethical clearance was given by the Institutional ethics committee (IHEC-LOP/2021/IM0376) with waiver of informed consent as data collection was anonymized.

\section{Data Collection}

Data were collected from medical records/ICU charts with a standardized data collection form. Demographics, admission information, indication of intubation and tracheostomy, dates of intubation, tracheostomy, decannulation, discharge or death were noted with tracheostomy complications, weaning details, treatment given, and mortality at 28 and 60 days.

On the day of admission, clinical data collected from ICU charts included vitals, laboratory variables, with sequential organ failure assessment (SOFA) score and respiratory oxygenation index (ROX) to assess severity of illness.

We also recorded pre-intubation and pre-TT arterial blood gas (ABG) parameters, post-intubation and pre-TT ventilatory parameters [fractional inspired oxygen concentration $\left(\mathrm{FiO}_{2}\right)$, plateau pressure $(\mathrm{Ppl})$, positive end expiratory pressure (PEEP), driving pressure (DP), and static compliance (Cst)]. Primary weaning attempt while intubated was noted with reason for weaning failure.

The type of tracheostomy procedure, i.e., percutaneous dilatational (PDT) or surgical (ST), surgical expertise, posttracheostomy complications including early (within 7 days) and late, were recorded from ICU charts and postdischarge follow-up in pulmonary OPD till 60 days of ICU admission. Increased oxygen requirement persisting $>1$-hour post-TT was also noted.

The number of tracheostomies downsized/decannulated was noted. Factors hindering weaning like tracheobronchial secretions (nil, minimal, or copious), VAP with culture positive microorganism, neurological, or circulatory causes along with duration needed for weaning from sedation, pressure support, decannulation, and mechanical ventilation were recorded.

Successful ventilator liberation defined as breathing without ventilator assistance on T-piece or Trach-vent during that index ICU admission was considered as weaning success. Decannulation was considered only if patient was able to breath unassisted spontaneously for $>48$ hours, without signs of infection, hemodynamic instability, GCS >14 with adequate upper airway access. The cause for weaning failure after tracheostomy (respiratory, circulatory, combined respiratory and circulatory, neurological, multiorgan involvement) was noted in detail. Mortality at 28 and 60 days of ICU admission, length of ICU, and hospital stay were recorded.

\section{Statistical Analysis}

Data were entered, cleaned, and coded in Microsoft excel 2013. Data analysis was done using IBM SPSS version 24. Continuous variables were summarized as mean (SD) when normally distributed and as median (IQR) when non-normally distributed. Categorical variables were summarized as $N(\%)$. Chi-square and Fischer exact test were used for testing association between categorical variables, while unpaired $t$ test/Mann-Whitney was used for testing association of continuous variables based on distribution.

For the primary objective, the clinical characteristics of the patients who required tracheostomy, tracheostomy data, complications, and weaning outcomes were summarized using
Source of support: Nil

Conflict of interest: None

descriptive statistics. We categorized the cohort into two groups (deceased and survivor) among the tracheostomized patients and studied the association of clinical parameters with 28-day mortality. For secondary objectives, we studied the association of complications and weaning outcomes with TT timing after intubation with $<7$ days as early and $>7$ days as late. We have taken tracheostomy within 7 days duration after intubation as early as per recommendations of ISCCM Expert Panel. ${ }^{8}$ Cox Proportional regression analysis was applied to calculate the hazard ratio among the predictors of mortality with $p$ value $<0.05$ as significant. Multivariate Cox regression was followed among the significant predictors from univariable Cox analysis to adjust for the confounders. Kaplan-Meir curve was drawn to plot the survival curves at different intervals from intubation to tracheostomy period.

\section{Results}

\section{Patients Flow and Baseline Characteristics}

During the study period, 4,050 COVID-19 patients were admitted in our institute with 597 patients (14.7\%) needing ICU care. Among these, 436 patients (73\%) needed invasive mechanical ventilation with the need for tracheostomy in 69 patients (15.8\%). Due to missing data of 4 tracheostomized patients, only 65 patients were included in the final analysis.

Patients undergoing tracheostomy $(n=65)$ were predominantly male patients $42(65 \%)$, with average age $51( \pm 14)$ years with at least one comorbidity present in $72.3 \%$ patients. Table 1 explains the baseline characteristics of tracheostomized patients.

\section{TT Procedure and Complications}

The most common indication of tracheostomy was weaning failure followed by anticipated prolonged ventilation, upper airway obstruction, and airway protection in 37 (57\%), 26 (40\%), $1(1.5 \%)$, and 1 (1.5\%) patients, respectively. Tracheostomy was performed in these 65 patients at a median (IQR) $6.0(4.0,8.0)$ days after intubation.

As a protocol, all tracheostomies were done at bedside in ICU with induced apnea. Ventilation was supported only if saturation on peripheral plethysmography fell below $90 \%$.

Numbers of PDT and ST performed were 45 (69\%) and 20 (31\%), respectively. Early and late complications were present in $46.6 \%$ and $4.4 \%$ PDT and $40 \%$ and $10 \%$ surgical tracheostomies, respectively. There was no difference in complications between the two techniques $(p=0.6)$ and TT timing $(p=0.3,>0.5)$. Table 2 shows the tracheostomy details like indication, type, expertise of surgeon, complications, weaning outcomes, duration of mechanical ventilation, ICU stay, and hospital stay.

\section{Weaning Outcomes}

Primary extubation was preferred, though was unsuccessful in 42/65 (65\%) patients. Primary weaning was not attempted in 23/65 (35\%) due to respiratory issues in 14 (22\%) patients, circulatory in 10 (15\%), neurological in $8(12 \%)$, both respiratory and circulatory in $6(9.2 \%)$ and airway obstruction in 1 (1.5\%) patient. 
Table 1: Baseline characteristics of tracheostomized patients $(N=65)$

\begin{tabular}{|c|c|c|c|c|}
\hline Characteristic & Overall, $N=65$ & Early within 7 days, $N=41$ & Late after 7 days, $N=24$ & $p$ \\
\hline Age & $53(40,62)$ & $55(43,65)$ & $45(38,54)$ & 0.043 \\
\hline Gender & & & & 0.2 \\
\hline Male & $42(65 \%)$ & $29(71 \%)$ & $13(54 \%)$ & \\
\hline Female & $23(35 \%)$ & $12(29 \%)$ & $11(46 \%)$ & \\
\hline \multicolumn{5}{|l|}{ Comorbidities } \\
\hline HTN & $30(46 \%)$ & $19(46 \%)$ & $11(46 \%)$ & $>0.9$ \\
\hline COPD & $1(1.5 \%)$ & $0(0 \%)$ & $1(4.2 \%)$ & 0.4 \\
\hline DM & $26(40 \%)$ & $19(46 \%)$ & $7(29 \%)$ & 0.2 \\
\hline$C A D$ & $5(7.8 \%)$ & $4(10 \%)$ & $1(4.2 \%)$ & 0.6 \\
\hline CLD & $0(0 \%)$ & $0(0 \%)$ & $0(0 \%)$ & $>0.9$ \\
\hline CKD & $4(6.2 \%)$ & $4(9.8 \%)$ & $0(0 \%)$ & 0.3 \\
\hline Hypothyroidism & $8(12 \%)$ & $4(9.8 \%)$ & $4(17 \%)$ & 0.5 \\
\hline Autoimmune & $0(0 \%)$ & $0(0 \%)$ & $0(0 \%)$ & $>0.9$ \\
\hline Malignancy & $2(3.1 \%)$ & $2(4.9 \%)$ & $0(0 \%)$ & 0.5 \\
\hline Cerebrovascular & $4(6.2 \%)$ & $3(7.3 \%)$ & $1(4.2 \%)$ & $>0.9$ \\
\hline Others & $6(9.2 \%)$ & $3(7.3 \%)$ & $3(12 \%)$ & 0.7 \\
\hline \multicolumn{5}{|l|}{ Duration based parameters in days } \\
\hline Symptom onset to admission & $5.00(4.00,9.00)$ & $5.00(4.00,10.00)$ & $4.00(3.00,7.50)$ & 0.077 \\
\hline Symptom onset to intubation & $9(5,11.5)$ & $10(5.5,14)$ & $7(5,11)$ & 0.246 \\
\hline Admission to intubation & $1.0(0.0,4.0)$ & $3.0(1.0,5.0)$ & $1.0(0.0,1.5)$ & 0.014 \\
\hline Symptom onset to tracheostomy & $15(12,20)$ & $14.5(11,18)$ & $17(12,20)$ & 0.525 \\
\hline Intubation to tracheostomy & $6.0(4.0,8.0)$ & $5.0(4.0,6.0)$ & $10.0(8.0,11.5)$ & $<0.001$ \\
\hline \multicolumn{5}{|l|}{ Severity of illness by SOFA score } \\
\hline At admission & $4.0(3.0,5.0)$ & $3.0(3.0,5.0)$ & $4.0(3.0,4.0)$ & 0.8 \\
\hline At intubation & $4.0(4.0,4.0)$ & $4.0(4.0,4.0)$ & $4.0(4.0,4.0)$ & 0.7 \\
\hline At tracheostomy & $3.0(3.0,4.0)$ & $3.0(3.0,4.0)$ & $3.0(3.0,5.0)$ & 0.7 \\
\hline VAP & $30(22 \%)$ & $22(20 \%)$ & $8(25 \%)$ & 0.6 \\
\hline \multicolumn{5}{|l|}{ Treatment } \\
\hline Vasopressor use & $40(62 \%)$ & $28(68 \%)$ & $12(50 \%)$ & 0.14 \\
\hline RRT & $5(7.7 \%)$ & $5(12 \%)$ & $0(0 \%)$ & 0.15 \\
\hline Antibiotic & 65 (100\%) & $41(100 \%)$ & $24(100 \%)$ & $>0.9$ \\
\hline Anticoagulant & 63 (97\%) & 39 (95\%) & $24(100 \%)$ & 0.5 \\
\hline Antifungal & $25(38 \%)$ & $13(32 \%)$ & $12(50 \%)$ & 0.14 \\
\hline Antiviral & $50(77 \%)$ & $33(80 \%)$ & 17 (71\%) & 0.4 \\
\hline Steroid use & 64 (98\%) & $40(98 \%)$ & $24(100 \%)$ & $>0.9$ \\
\hline
\end{tabular}

"Continuous variable as median (IQR) and categorical as $n(\%)$

After tracheostomy, weaning success and ventilator liberation were achieved in 35 (54\%) patients at an average of $14.9( \pm 18.7)$ days (range 1-34 days). Weaning after TT was challenging with common reasons for weaning failure being respiratory (poor compliance), neurological (delirium, agitation, poor cognition), circulatory causes (poor left ventricular contractility, septic shock with hemodynamic instability), and both respiratory and circulatory issues in 19 (31\%), 11 (18\%), 9 (15\%), and 5 (8.2\%) patients, respectively. We observed VAP in $22 \%$ patients with Acinetobacter baumannii, grown most commonly in cultures followed by Klebsiella pneumoniae, Elizabethkingia meningoseptica, and Burkholderia cepacian.

Sedation was weaned in 51 (78\%) patients at median duration of $2.0(0.5,4.0)$ days post-tracheostomy. Nearly $14(22 \%)$ patients had their tracheostomy tube downsized and 32 (49\%) trachea were decannulated with mean time from TT of $9.7( \pm 8.3)$ days ranging from 4 to 34 days. The median duration of mechanical ventilation, ICU stay, and hospital stay is mentioned in Table 3.

\section{Mortality at 28 days}

At the end of study period, all study patients were discharged or deceased at 60 days of ICU admission. Outcome data were available for all 65 tracheostomized patients. Mortality at 28 days was 30/65 (46.1\%) and 60 days was 35/65 (53.8\%) patients.

Supplementary Table 1 shows the description and association of admission (vitals, laboratory, $\mathrm{ROX}, \mathrm{pH}, \mathrm{FiO}_{2}$ ), intubation and tracheostomy ( $\mathrm{ABG}$ and ventilatory) parameters, and treatment with mortality. At admission, deceased patients had a lower diastolic blood pressure ( $p=0.038)$ and higher blood sugar levels $(p=0.051)$, though SOFA score and ROX were similar. At tracheostomy, $\mathrm{FiO}_{2}$ was lower $(0.4-0.6, p=0.015)$, and $\mathrm{PaO}_{2} / \mathrm{FiO}_{2}$ was higher (118-200, 
Table 2: Tracheostomy procedure-related parameters and complications

\begin{tabular}{|c|c|c|c|c|}
\hline Characteristic & Overall, $N=65$ & Early within 7 days, $N=41$ & Late after 7 days, $N=24$ & $p$ \\
\hline \multicolumn{5}{|l|}{ Indication of tracheostomy } \\
\hline Poor lung compliance & $26(40 \%)$ & $21(65.6 \%)$ & $5(15.2 \%)$ & $<0.001$ \\
\hline Weaning failure & $37(57 \%)$ & $9(28.2 \%)$ & $28(84.8 \%)$ & \\
\hline Upper airway obstruction & $1(1.5 \%)$ & $1(3.1 \%)$ & 0 & \\
\hline Airway protection & $1(1.5 \%)$ & $1(3.1 \%)$ & 0 & \\
\hline TT procedure type & & & & 0.8 \\
\hline Surgical & $20(31 \%)$ & $13(32 \%)$ & $7(29 \%)$ & \\
\hline Percutaneous & $45(69 \%)$ & $28(68 \%)$ & $17(71 \%)$ & \\
\hline TT done by & & & & 0.3 \\
\hline Intensivist & $34(52 \%)$ & $22(54 \%)$ & $12(50 \%)$ & \\
\hline General surgeon & $16(25 \%)$ & $12(29 \%)$ & $4(17 \%)$ & \\
\hline ENT surgeons & $15(23 \%)$ & $7(17 \%)$ & $8(33 \%)$ & \\
\hline Increased oxygen requirement post TT & $31(48 \%)$ & $17(41 \%)$ & $14(58 \%)$ & 0.2 \\
\hline Procedural complications & $29(45 \%)$ & $18(44 \%)$ & $11(46 \%)$ & 0.9 \\
\hline Early complications & & & & 0.308 \\
\hline None & $36(65 \%)$ & $23(62 \%)$ & $13(72 \%)$ & \\
\hline Bleeding & $19(29.2 \%)$ & $13(31.7 \%)$ & $6(25 \%)$ & \\
\hline Pneumothorax & $3(4.6 \%)$ & $2(4.9 \%)$ & $1(4.2 \%)$ & \\
\hline Hemodynamic instability & $1(1.5 \%)$ & $1(2.4 \%)$ & 0 & \\
\hline Subcutaneous emphysema & $3(4.6 \%)$ & $2(4.9)$ & $1(4.2 \%)$ & \\
\hline Infections & $3(4.6 \%)$ & 0 & $3(12.5 \%)$ & \\
\hline Late complications & & & & $>0.9$ \\
\hline None & $61(97 \%)$ & $37(95 \%)$ & $24(100 \%)$ & \\
\hline Swallowing difficulty & $1(1.5 \%)$ & $1(2.4 \%)$ & $0(0 \%)$ & \\
\hline Stridor & $1(1.5 \%)$ & $1(2.4 \%)$ & $0(0 \%)$ & \\
\hline Stenosis & $2(4.9 \%)$ & $2(4.9 \%)$ & $0(0 \%)$ & \\
\hline \multicolumn{5}{|l|}{ TT secretions } \\
\hline Absent & $11(17 \%)$ & $8(20 \%)$ & $3(12 \%)$ & 0.7 \\
\hline Minimal & $28(43 \%)$ & $16(39 \%)$ & $12(50 \%)$ & \\
\hline Copious & $26(40 \%)$ & $17(41 \%)$ & $9(38 \%)$ & \\
\hline
\end{tabular}

Table 3: Weaning characteristics and time-based outcomes after overall, early and late tracheostomy

\begin{tabular}{lcccc}
\hline Characteristic & Overall, $N=65$ & Early within 7 days, $N=41$ & Late after 7 days, $N=24$ & $p$ \\
\hline Sedation wean & $2.0(0.5,4.0)$ & $2.0(0.0,4.0)$ & $2.5(1.0,5.8)$ & 0.12 \\
Days on pressure support mode & $15.0(12.0,19.0)$ & $14.0(12.0,19.0)$ & $16.5(12.8,20.2)$ & 0.3 \\
TT to ventilator liberation & $7(5-11)$ & $6(4-10)$ & $9(5-16)$ & 0.2 \\
Decannulation success & $32(49 \%)$ & $18(44 \%)$ & $14(58 \%)$ & 0.3 \\
Tracheostomy to decannulation & $13(8-20)$ & $13(8-20)$ & $13(7-20)$ & 0.8 \\
duration & & & & \\
Duration of mechanical ventilation & $14(9,18)$ & $11(8,16)$ & $16(14,22)$ & 0.001 \\
Duration of ICU stay & $20(14,26)$ & $16(13,24)$ & $24(19,32)$ & 0.013 \\
Duration of hospital stay & $23(18,32)$ & $21(16,28)$ & $28(22,36)$ & 0.014 \\
\hline
\end{tabular}

$p=0.033$ ) in survivors. Compliance though higher in survivors did not reach statistical significance $(p=0.074)$. Treatment was similar except for higher vasopressor use in nonsurvivors $(p<0.001)$.

Tracheostomy was downsized and decannulated significantly more in survivors in 13/35 (37\%) and 30/35 (86\%), respectively. Length of critical care and hospital stay was longer in survivors, though post-tracheostomy ICU stay was shorter (Table 4).

\section{Predictors of Mortality}

We used Cox-PH model to identify predictors of mortality among the tracheostomized $(N=65)$ patients (Table 4) with event as 28-day mortality and time refers to intubation to tracheostomy duration. The parameters like late tracheostomy (HR 0.04, $p=0.001)$, sedation weaning, downsizing, and decannulation were found to increase the survival outcomes in tracheostomized patients. 
Outcomes after Tracheostomy in COVID-19 in Central India

Table 4: Details of predictors of mortality stratified by certain tracheostomy parameters

\begin{tabular}{|c|c|c|c|c|c|c|}
\hline Characteristic & Overall, $N=65$ & Deceased, $N=30$ & Survived, $N=35$ & $\begin{array}{c}\text { Unadjusted hazard } \\
\text { ratio }\end{array}$ & $p$ & $95 \% \mathrm{Cl}$ \\
\hline Age & $51.1(31.6)$ & $52(15)$ & $51(13)$ & 1.01 & 0.3 & $0.99-1.04$ \\
\hline \multicolumn{7}{|l|}{ Gender } \\
\hline Male & $42(65 \%)$ & $20(67 \%)$ & $22(63 \%)$ & 1.42 & 0.4 & $0.66-3.07$ \\
\hline Female (ref) & $23(35 \%)$ & $10(33 \%)$ & $13(37 \%)$ & - & - & - \\
\hline \multicolumn{7}{|l|}{ Presence of comorbidities } \\
\hline Yes & $42(64.6 \%)$ & $20(66.6 \%)$ & $22(62.9 \%)$ & 1.5 & 0.4 & $0.63-3.53$ \\
\hline \multicolumn{7}{|l|}{ Type of tracheostomy } \\
\hline Surgical & & $13(31.7 \%)$ & $7(29.2 \%)$ & 0.85 & 0.7 & $0.38-1.86$ \\
\hline Percutaneous & & $28(68.3 \%)$ & $17(70.8 \%)$ & - & - & - \\
\hline \multicolumn{7}{|c|}{ Ventilatory parameters pretracheostomy } \\
\hline $\mathrm{FiO}_{2}$ & $0.50(0.50,0.60)$ & $0.58(0.50,0.70)$ & $0.50(0.40,0.60)$ & 2.54 & 0.3 & $0.36-18.02$ \\
\hline $\mathrm{P} / \mathrm{F}$ & $140(109,168)$ & $124(98,157)$ & $148(118,200)$ & 0.99 & 0.5 & $0.99-1.01$ \\
\hline $\mathrm{DP}\left(\mathrm{cm} \mathrm{H}_{2} \mathrm{O}\right)$ & $15.0(12.0,19.0)$ & $16.0(13.0,20.0)$ & $14.0(12.0,19.0)$ & 0.95 & 0.2 & $0.88-1.02$ \\
\hline Compliance $\left(\mathrm{mL} / \mathrm{cm} \mathrm{H}_{2} \mathrm{O}\right)$ & $24(19,29)$ & $23(16,29)$ & $25(20,30)$ & 0.98 & 0.3 & $0.93-1.02$ \\
\hline PEEP $\left(\mathrm{cm} \mathrm{H}_{2} \mathrm{O}\right)$ & $8.0(6.0,8.0)$ & $8.0(8.0,8.0)$ & $8.0(6.0,8.0)$ & 1.08 & 0.5 & $0.84-1.40$ \\
\hline \multicolumn{7}{|l|}{ Severity of illness } \\
\hline SOFA admission & $4.0(3.0,5.0)$ & $3.0(3.0,4.0)$ & $4.0(3.0,5.0)$ & 0.94 & 0.6 & $0.74-1.19$ \\
\hline SOFA tracheostomy & $3.0(3.0,4.0)$ & $4.0(3.0,4.0)$ & $3.0(3.0,4.0)$ & 1.14 & 0.2 & $0.89-1.45$ \\
\hline VAP & $14(22 \%)$ & $7(23 \%)$ & $7(21 \%)$ & 1.44 & 0.3 & $0.70-0.97$ \\
\hline \multicolumn{7}{|l|}{ Tracheostomy secretions } \\
\hline Absent (ref) & $11(17 \%)$ & $6(20 \%)$ & $5(14 \%)$ & - & - & - \\
\hline Minimal & $28(43 \%)$ & $14(47 \%)$ & $14(40 \%)$ & 0.81 & 0.7 & $0.30-2.18$ \\
\hline Copious & $26(40 \%)$ & $10(33 \%)$ & $16(46 \%)$ & 0.67 & 0.5 & $0.24-1.88$ \\
\hline Tracheostomy complications & $29(45 \%)$ & $13(43 \%)$ & $16(46 \%)$ & 1.04 & 0.9 & $0.50-2.14$ \\
\hline Vasopressor use & $40(62 \%)$ & $25(83 \%)$ & $15(43 \%)$ & 3.98 & 0.008 & $1.40-9.75$ \\
\hline \multicolumn{7}{|c|}{ Duration based parameters prior to tracheostomy (in days) } \\
\hline Symptom onset to admission & $5.00(4.00,9.00)$ & $5.00(3.00,9.50)$ & $5.00(4.00,8.50)$ & 0.99 & 0.9 & $0.90-0.10$ \\
\hline Admission to intubation & $1.0(0.0,4.0)$ & $2.0(1.0,4.8)$ & $1.0(0.0,4.0)$ & 1.01 & 0.8 & $0.92-0.11$ \\
\hline Symptom onset to intubation & $9(5.0,11.5)$ & $8.5(6.0,13.0)$ & $9(5.0,11.0)$ & 1.04 & 0.3 & $0.96-1.11$ \\
\hline $\begin{array}{l}\text { Symptom onset to } \\
\text { tracheostomy }\end{array}$ & $15(12-20)$ & $15(11-20)$ & $16(12-20)$ & 0.91 & 0.02 & $0.83-0.96$ \\
\hline Early tracheostomy (ref) & $41(63 \%)$ & $21(70 \%)$ & $20(57 \%)$ & - & - & - \\
\hline Late tracheostomy & $24(37 \%)$ & $9(30 \%)$ & $15(43 \%)$ & 0.04 & 0.001 & $0.01-0.27$ \\
\hline Sedation wean duration & $2.0(0.5,4.0)$ & $0.2(0.0,2.8)$ & $3.0(1.0,4.5)$ & 0.81 & 0.014 & $0.69-0.96$ \\
\hline Downsized & $14(22 \%)$ & $1(3.3 \%)$ & $13(37 \%)$ & 0.12 & 0.038 & $0.02-0.89$ \\
\hline Decannulation & $32(49 \%)$ & $2(6.7 \%)$ & $30(86 \%)$ & 0.06 & 0.001 & $0.02-0.26$ \\
\hline $\begin{array}{l}\text { Tracheostomy to } \\
\text { decannulation duration }\end{array}$ & $0(0,12)$ & $0(0,0)$ & $10(6,18)$ & 0.85 & 0.002 & $0.76-0.94$ \\
\hline \multicolumn{7}{|c|}{ Outcome-based parameters (in days) } \\
\hline $\begin{array}{l}\text { Tracheostomy to ventilator } \\
\text { liberation }\end{array}$ & $3(0,8)$ & $0(0,0)$ & $6(4,10)$ & 0.79 & 0.002 & $0.66-0.92$ \\
\hline Post tracheostomy ICU days & $11(7,16)$ & $10(4,14)$ & $12(10,20)$ & 0.93 & 0.013 & $0.87-0.98$ \\
\hline Duration of ICU days & $20(14-26)$ & $16(13-24)$ & $24(19-33)$ & 0.89 & 0.001 & $0.83-0.95$ \\
\hline Hospital stay duration & $23(18,32)$ & $19(15,23)$ & $30(21,40)$ & 0.88 & 0.001 & $0.84-0.94$ \\
\hline
\end{tabular}

Based on the results of univariate cox regression analysis and clinical relevance we performed forward step-wise Cox-PH multivariate regression. The results showed that of all the variables, tracheostomy after 7 days of intubation (HR: 0.3 , 95\% Cl: $0.13-0.68, p=0.004)$ and decannulation (HR: $0.05,95 \%$ $\mathrm{Cl}: 0.01-0.22, p<0.001)$ increased the survival probability in tracheostomized patients. Prognostic factors associated with poor survival identified were only use of vasopressors (HR: 3.98, 95\% Cl: 1.40-9.75, $p=0.008)$.

Kaplan-Meir curve plots the days of intubation to tracheostomy against $x$-axis and the cumulative 28-day survival and 60-day survival probability against $y$-axis in Figures 1 and 2 . There were two survival curves drawn representing patients who underwent early and late tracheostomy. For every point at which the death 


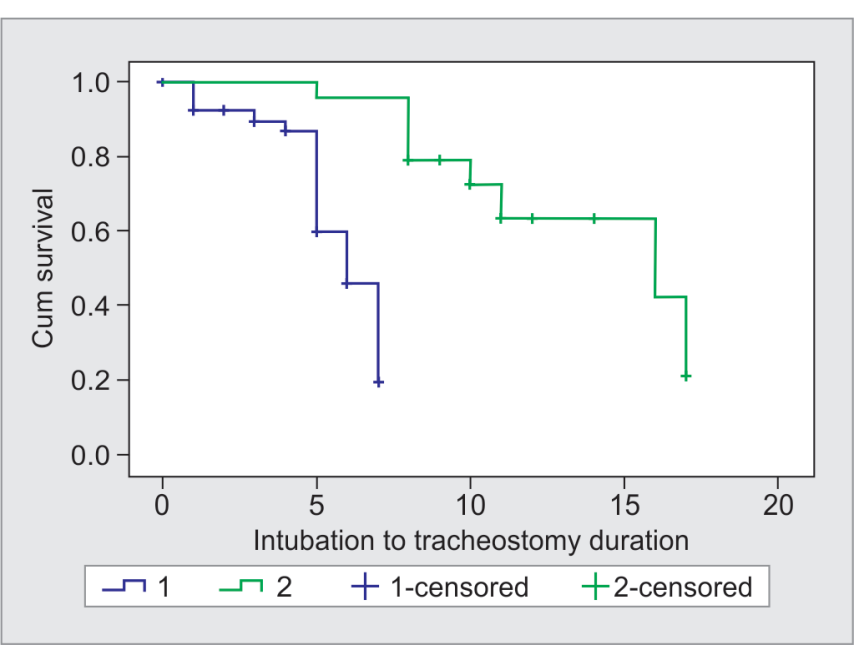

Fig. 1: Kaplan-Meir analysis of survival in patients receiving early and late tracheostomies for 28 days. In this figure, the event was considered death $(n=35)$ and those who had survived $(n=35)$ were taken in censored data. The mean of 28 days survival was found to be 5.6 days considering the largest survival time days with $95 \%$ confidence interval between (5.1-6.2) days in early and 13.7 days with $95 \% \mathrm{Cl}(11.8-15.7)$ in late tracheostomized patients

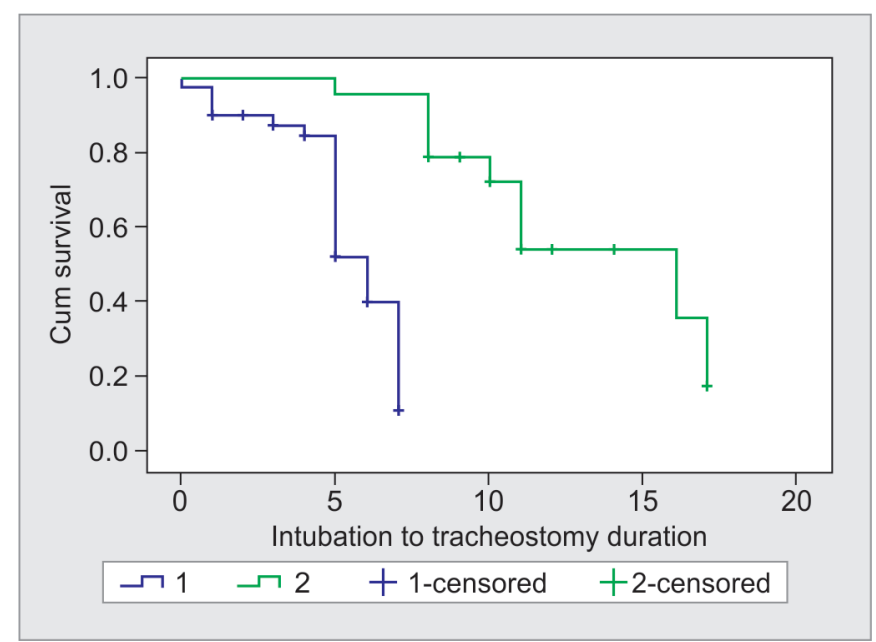

Fig. 2: Kaplan-Meir analysis of survival in patients receiving early and late tracheostomies for 60 days. In this figure, the event was considered death $(n=35)$ and those who had survived $(n=30)$ were taken in censored data. The mean 60 days survival was found to be 5.4 days considering the largest survival time days with $95 \%$ confidence interval between $4.8-6.0$ days in early and 13.2 days with $95 \% \mathrm{Cl}(11.2-15.2)$ in late tracheostomized patients

occurs there is a drop in the curve and the cumulative survival at that point was read against $y$-axis. From the Figures 1 and 2, it was evident that better survival was present after late as compared to early tracheostomy with significance in log rank test $(p<0.001)$.

\section{Association of Clinical Characteristics and Weaning Outcomes with Timing of Tracheostomy (Early vs Late)}

Early and late tracheostomy was done in 41 and 24 patients, respectively. Though SOFA score $(p=0.8)$ was similar, early tracheostomy was done in older $(p=0.043)$, with longer admission to intubation duration ( $p=0.014$ ), though duration from symptom onset to intubation was similar (Table 1). The patients tracheostomized after 7 days had the benefit of early intubation after admission, in view of higher $\mathrm{FiO}_{2}$ requirement at admission and lower $\mathrm{PaO}_{2} / \mathrm{FiO}_{2}$ ratio $(<100)$ at intubation.

Supplementary Table 2 shows the description and association of admission parameters ( $\mathrm{ROX}, \mathrm{pH}, \mathrm{FiO}_{2}$ ), intubation and tracheostomy (ABG and ventilatory) parameters with timing of tracheostomy (early vs late). Patients with lower $\operatorname{ROX}(p=0.016)$ and higher oxygen requirement $(p<0.001)$ at admission and higher oxygen requirement $(p<0.001)$ and driving pressure $(p=0.034)$ after intubation with poorer $\mathrm{P} / \mathrm{F}$ ratio $(p=0.014)$ were tracheostomized late.

The complication rate was similar for early $(p=0.308)$ and late $(p>0.5$ ) tracheostomies (Table 2). Late tracheostomy was associated with longer duration of mechanical ventilation $(p=0.001)$, ICU stay $(p=0.013)$, and hospital stay $(p=0.014)$ (Table 3$)$.

\section{Discussion}

In this retrospective observational cohort study of 65 tracheostomized COVID-19 patients, we observed that:

- Most common indication of TT was weaning failure followed by anticipated prolonged ventilation, airway protection, and upper airway obstruction.

- Bleeding from tracheostomy site was the most common early complication followed by pneumothorax, subcutaneous emphysema, stoma site infection, and hemodynamic instability. Among late complications, tracheal stenosis was the most frequent followed by stridor and swallowing difficulty. There was no difference in complication rates between early and late tracheostomy. There was no difference in complications or mortality at 28 days between PDT and ST.

- Ventilator liberation was successful in 35/65 (54\%) patients at an average of $14.9( \pm 18.7)$ days after tracheostomy. Overall, $49 \%$ patients were decannulated. Mortality was $46.1 \%$ (30/65) at 28 days and $53.8 \%$ at 60 days of ICU admission.

- Early tracheostomy within 7 days of intubation did not facilitate early ventilator liberation and was not associated with survival benefit.

Intensive care of tracheostomized COVID-19 patients is challenging. Most frequent indication of tracheostomy documented in our ICU was weaning failure (57\%), followed by anticipated prolonged ventilation (40\%), airway protection (1.5\%), and upper airway obstruction (1.5\%). Pneumonia needing prolonged ventilation followed by weaning difficulty was reported as the most common indication of TT in a case series of 11 COVID-19 patients from India. ${ }^{9}$

\section{Complications Associated with Tracheostomy}

Incidence of complications after tracheostomy is reported from 0 to $40 \%$ for PDT and 7-58\% for open surgical tracheostomies. ${ }^{10,11}$ Picetti et al. reported stoma infection and hemorrhage as the common complication in 66 COVID-19 ICU patients who underwent tracheostomy 6 days after intubation. ${ }^{12}$ We observed an early and late complication rate of 46.6 and $4.4 \%$ for PDT and 40 and $10 \%$ for surgical tracheostomy, respectively. Perioperative hemorrhage was the most common complication (29.2\%) in surgical as well as PDT as is previously reported. ${ }^{3}$ Though we withheld therapeutic dose, low molecular weight heparin 24 hours prior to procedure as a protocol, still the presence of a hypocoagulative state (DIC like state), with 
increase in proinflammatory cytokines, coagulation disorders, and endothelial and microvascular damage, may have contributed to the bleeding complication.' In most patients, bleeding was managed conservatively, except one where surgical intervention was needed.

\section{Weaning Outcomes after Tracheostomy}

Tracheostomy in COVID-19 patient should be more beneficial due to the poor lung compliance, anticipated prolonged mechanical ventilation, muscle weakness with overwhelming secretions, poor cough, and chance of reintubation. Patients with COVID-19 may need respiratory support for more than 4 weeks. ${ }^{13}$ In our patient cohort, average duration of mechanical ventilation was 14 days. We practiced immediate proning after intubation. Tracheostomy was considered when there was no response to proning even after 3-4 cycles.

Static lung compliance in our patient cohort was poor (18-30 $\mathrm{mL} / \mathrm{cm} \mathrm{H}_{2} \mathrm{O}$ ) at intubation with slight improvement till tracheostomy. Even before tracheostomy lung compliance was low ( $24 \mathrm{~mL} / \mathrm{cm} \mathrm{H}_{2} \mathrm{O}$ ) with a mean DP and PEEP of 15 and 8, respectively. The mean $\mathrm{FiO}_{2}$ requirement improved from 0.75 at intubation to 0.5 at tracheostomy, signifying improvement in oxygenation despite only slight improvement in lung compliance. Ideal condition of tracheostomy with $\mathrm{FiO}_{2}<0.4$ and near normal compliance was not achievable in COVID-19.

After tracheostomy, 54\% patients were weaned successfully within a range of 1-34 days. Similar weaning success rate was reported by the COVID Trach collaborative group from UK NHS $(52 \% ; n=219 / 465)$ and Spain $(52.1 \% ; 842 / 1616){ }^{14}$

Decannulation was successful in $49 \%$ patients at $4-34$ days after tracheostomy in our study. Another retrospective study from India reported decannulation 16-32 days after TT in 22 tracheostomized COVID-19 patients. $^{15}$

We observed that ventilator weaning was challenging even after tracheostomy because of neurological (delirium, agitation) and circulatory (myocarditis, hemodynamic instability, poor LV function) reasons, besides respiratory issues. Ventilator asynchrony and agitation were the main contributor for ongoing sedation post-TT.

\section{Mortality Rates}

Highest mortality rates after tracheostomy in COVID-19 patients are reported from Spain (24-41\%), followed by United States of America (6-33\%), Italy (18-25\%), and United Kingdom (12-14\%). ${ }^{14,16}$ A small study from India reported 59\% mortality in 22 tracheostomized patients. ${ }^{17}$ We observed a lower mortality rate of $46.1 \%(30 / 65)$ at 28 days of ICU admission with increase to $53.8 \%$ at 60 days. Our mortality rate is higher than that in western literature. It is not surprising as countries with a high health expenditure of roughly $7.6 \%$ gross domestic product (GDP) have a lower COVID-19 fatality rate. $^{18}$

There was no association of mortality with elderly age and presence of comorbidities. Our findings agree with Volo et al. while being in contrast with Grasselli et al. ${ }^{19,20}$ Average SOFA score at admission was 3 in deceased tracheostomized patients with a poor lung compliance ( $\mathrm{Cst} 22 \mathrm{~mL} / \mathrm{cm} \mathrm{H}_{2} \mathrm{O}$ ). Most outcome studies on tracheostomy have not highlighted the ventilatory parameters at tracheostomy.

\section{Outcomes with Respect to Timing of Tracheostomy}

In COVID-19, definitions for early and late tracheostomy are dynamic with duration ranging from 7 to 14 days after intubation in different studies. ${ }^{19,21-23}$ Earlier recommendations deferred tracheostomy beyond 21 days of intubation to decrease the risk of infection to healthcare workers (HCWs). ${ }^{24,25}$ Volo et al. suggested to wait at least 14 days before tracheostomy with postponement of procedure with SOFA score $>6 .{ }^{19}$ Angel et al. and Consensus group have favored tracheostomy around 10th day of intubation with maximal utilization of ICU resources in patients with clinical improvement. ${ }^{26,27}$

In Indian scenario, small case series have reported early tracheostomy within 4-12 days after intubation in COVID-19, most likely due to overcrowded ICU with high demand of ventilatory equipment in a pandemic. 6,28

Previous studies have suggested that early tracheostomy is beneficial in Acute Respiratory Distress Syndrome (ARDS) patients on mechanical ventilation with decrease in the length of ICU stay and improved survival. ${ }^{29}$ In our cohort of COVID-19 patients with ARDS, we observed no difference in frequency of VAP and duration taken for weaning-off sedation, pressure support ventilation, ventilator liberation, and decannulation post-tracheostomy between early and late group. We observed that the decision of tracheostomy after 7 days of intubation, once $\mathrm{FiO}_{2}$ requirement was reduced to 0.5 , was associated with better survival. This was despite higher oxygen requirement and poorer oxygenation at the time of intubation with need for early intubation in these patients, which may have influenced survival. Though mortality cannot be attributed to the procedure of Tracheostomy per se, still we hypothesize that early tracheostomy within 7 days did not have weaning or survival benefit as the primary disease process was still evolving. In COVID-19, patients may develop lung "hyperinflammation," partly due to viral infection, bacterial superinfection, ventilator-induced lung injury or patient self-inflicted lung injury (P-SILI), heart failure, or a combination of these factors. ${ }^{30}$ Once there is improvement in oxygenation to $\mathrm{FiO}_{2}$ requirement less than 0.5 , in spite of only slight improvement in lung compliance, it may denote resolution of some pulmonary pathophysiological changes associated with COVID-19. It may be prudent to wait for 7 days after intubation, so that the tracheostomy facilitates weaning from sedation and ventilator liberation, thereby contributing to better outcomes.

\section{Limitations}

Our study is limited by the retrospective nature, small sample size, single-center design which limits the generalizability of our results to a wider population. As our center is the primary referral center in Central India, our results may possibly be generalized to Madhya Pradesh and neighboring states. Our study may serve as a pilot for future studies on outcome of tracheostomized COVID-19 patients on mechanical ventilation.

Retrospective nature of data collection from electronic medical records has the limitation of affecting data accuracy. Since most data were collected from ICU charts where hourly records of minute details of clinical course are stringently maintained, we hope to have decreased the recall bias. Data were collected by two investigators to increase data reliability.

Further, we have not studied the impact on HCWs in terms of infectivity. Peak infectivity is demonstrated by SARS coronavirus at 9-10 days after symptom onset, but novel coronavirus may have peak infectivity from 2 days prior to symptom onset, with decreasing infectivity thereafter. ${ }^{31-33}$ Because of prevalent community spread in Central India, we did not include COVID-19 infections in HCW as causality with tracheostomy could not be ascertained. 


\section{Strength of the Study}

All the study patients were followed till 60 days of ICU admission with everyone discharged or deceased by the time of data entry giving clear outcome results.

We studied ventilatory mechanics of static compliance, $\mathrm{FiO}_{2}$, DP, PEEP post-intubation, and pre-tracheostomy which may help in making evidence-based decisions before performing tracheostomy.

We have included elaborate findings of tracheostomy type and timing, weaning details which can contribute in prognostication in tracheostomized COVID-19 patients on mechanical ventilation.

\section{Conclusion}

Weaning success in tracheostomized COVID-19 patients in our study was comparable to western literature. In COVID-19 patients on invasive mechanical ventilation, no weaning or survival benefit was seen with early tracheostomy. Moreover, tracheostomy should be done only after $\mathrm{FiO}_{2}$ requirement decreases to 0.5 with a PEEP $\leq 8$ for better outcomes and to avoid a wasted procedure.

\section{OrCID}

Sunaina Tejpal Karna @ https://orcid.org/0000-0002-4200-5948 Saurabh Trivedi (1) https://orcid.org/0000-0003-1997-6591 Pooja Singh @ ittps://orcid.org/0000-0003-0556-7359 Alkesh Khurana @ i https://orcid.org/0000-0002-9646-4971 Revadi Gouroumourty (D https://orcid.org/0000-0002-9646-4971 Brahmam Dodda ๑ https://orcid.org/0000-0003-1127-2629 Saurabh Saigal @ https://orcid.org/0000-0002-2364-2271 Jai Prakash Sharma @ https://orcid.org/0000-0003-4147-1637 Amit Karna @ i https://orcid.org/0000-0001-8434-0982 Pranav Shrivastava @ https://orcid.org/0000-0003-1637-1271 Aqeel Hussain @ https://orcid.org/0000-0003-2596-2524 Vikas Gupta @ https://orcid.org/0000-0002-7610-7141 Gankalyan Behera (1) https://orcid.org/0000-0002-9155-285X Vaishali Waindeskar (1) https://orcid.org/0000-0002-0556-7159

\section{References}

1. Battaglini D, Missale F, Schiavetti I, Filauro M, lannuzzi F, Ascoli A, et al. Tracheostomy timing and outcome in severe COVID-19: the WeanTrach multicenter study. J Clin Med 2021;10(12):2651. DOI: 10.3390/jcm10122651.

2. Benito DA, Bestourous DE, Tong JY, Pasick LJ, Sataloff RT. Tracheotomy in COVID-19 patients: a systematic review and meta-analysis of weaning, decannulation, and survival. Otolaryngol Head Neck Surg 2021;194599820984780. DOI: 10.1177/0194599820984780.

3. Tang Y, Wu Y, Zhu F, Yang X, Huang C, Hou G, et al. Tracheostomy in 80 COVID-19 patients: a multicenter, retrospective, observational study. Front Med (Lausanne) 2020;7:615845. DOI: 10.3389/ fmed.2020.615845.

4. Radhakrishnan S, Perumbally HA, Surya S, Ponneth MS. Guidelines for surgical tracheostomy and tracheostomy tube change during the COVID-19 pandemic: a review article. Indian J Otolaryngol Head Neck Surg 2020;72(3):398-401. DOI: 10.1007/s12070-020-01893-y.

5. Bindra A, Kajal S, Sikka K. Tracheostomy during COVID-19 pandemic. J Neuroanaesthesiol Crit Care 2020;7(03):154-157. DOI: 10.1055/ s-0040-1716428.

6. Pradhan P, Mishra AK, Mittal Y, Nayak A, Preetam C, Sarkar S, et al. Tracheostomy in the COVID19 patients: our experience in 12 cases. Indian J Otolaryngol Head Neck Surgery 2021;1-5. DOI: 10.1007/ s12070-021-02375-5.
7. Sahu A, Swain SK, Das SR. Performing bedside surgical tracheostomy on COVID-19 patients at intensive care unit-our experiences at a tertiary care Indian teaching hospital. Eur J Mol Clin Med 2020;7(11):1208-1217.

8. Gupta S, Dixit S, Choudhry D, Govil D, Mishra RC, Samavedam S, et al. Tracheostomy in adult intensive care unit: an ISCCM expert panel practice recommendations. Indian J Crit Care Med 2020;24(Suppl. 1): S31-S42. DOI: 10.5005/jp-journals-10071-G23184.

9. Mishra P, Jedge P, Kaushik M, Artham P, Kumari S. Our experience of tracheostomy in COVID-19 patients. Indian J Otolaryngol Head Neck Surg 2020;1-4. DOI: 10.1007/s12070-020-02036-z.

10. Spataro E, Durakovic N, Kallogjeri D, Nussenbaum B. Complications and 30-day hospital readmission rates of patients undergoing tracheostomy: a prospective analysis. Laryngoscope 2017;127(12): 2746-2753. DOI: 10.1002/lary.26668.

11. Delaney A, Bagshaw SM, Nalos M. Percutaneous dilatational tracheostomy versus surgical tracheostomy in critically ill patients: a systematic review and meta-analysis. Crit Care 2006;10(2):R55. DOI: 10.1186/cc4887.

12. Picetti E, Fornaciari A, Taccone FS, Malchiodi L, Grossi S, Di Lella F, et al. Safety of bedside surgical tracheostomy during COVID-19 pandemic: a retrospective observational study. PLoS One 2020;15(9):e0240014. DOI: 10.1371/journal.pone.0240014.

13. Martin-Villares C, Perez Molina-Ramirez C, Bartolome-Benito M, Bernal-Sprekelsen M; COVID ORL ESP Collaborative Group (*). Outcome of 1890 tracheostomies for critical COVID-19 patients: a national cohort study in Spain. Eur Arch Otorhinolaryngol 2021;278(5):1605-1612. DOI: 10.1007/s00405-020-06220-3.

14. COVIDTrach collaborative. COVIDTrach; the outcomes of mechanically ventilated COVID-19 patients undergoing tracheostomy in the UK: Interim Report. Br J Surg 2020;107(12):e583-e584. DOI: 10.1002/ bjs. 12020.

15. AhmedY,Cao A, Thal A, Shah S, KinkhabwalaC, LiaoD, etal.Tracheotomy outcomes in 64 ventilated COVID-19 patients at a high-volume center in Bronx, NY. Laryngoscope 2021;131(6):E1797-E1804. DOI: 10.1002/lary.29391.

16. Riestra-Ayora J, Yanes-Diaz J, Penuelas O, Molina-Quiros C, SanzFernández R, Martin-Sanz E. Safety and prognosis in percutaneous vs surgical tracheostomy in 27 patients with COVID-19. Otolaryngol Head Neck Surg 2020;163(3):462-464. DOI: 10.1177/0194599820931801.

17. Swain SK, Acharya S. Bedside tracheostomy on COVID-19 patients in the intensive care unit: a retrospective study. Airway 2021;4(1):28-34. DOI: 10.4103/arwy.arwy_62_20.

18. Coccia M. Which are factors determining a low COVID-19 mortality in society? High health expenditure and lower exposure of population to air pollution as critical factors for an effective strategy to cope with future pandemics similar to COVID-19. 2020. DOI: 10.21203/ rs.3.rs-137207/v1.

19. Volo T, Stritoni P, Battel I, Zennaro B, Lazzari F, Bellin M, et al. Elective tracheostomy during COVID-19 outbreak: to whom, when, how? Early experience from Venice, Italy. Eur Arch Otorhinolaryngol 2021;278(3):781-789. DOI: 10.1007/s00405-020-06190-6.

20. Grasselli G, Zangrillo A, Zanella A, Antonelli M, Cabrini L, Castelli A, et al. Baseline Characteristics and outcomes of 1591 patients infected with SARS-CoV-2 admitted to ICUs of the Lombardy Region, Italy. JAMA 2020;323(16):1574-1581. DOI: 10.1001/jama.2020.5394 [published correction appears in JAMA 2021;325(20):2120].

21. Dochi H, Nojima M, Matsumura M, Cammack I, Furuta Y. Effect of early tracheostomy in mechanically ventilated patients. Laryngoscope Investig Otolaryngol 2019;4(3):292-299. DOI: 10.1002/lio2.265.

22. Adly A, Youssef TA, El-Begermy MM, Younis HM. Timing of tracheostomy in patients with prolonged endotracheal intubation: a systematic review. Eur Arch Otorhinolaryngol 2018;275(3):679-690. DOI: 10.1007/s00405-017-4838-7.

23. Obata K, Miyata R, Yamamoto K, Byn-Ya N, Kasai T, Inoue H, et al. Tracheostomy in patients with COVID-19: a single-center experience. In Vivo 2020;34(6):3747-3751. DOI: 10.21873/invivo.12224. 
24. Miles BA, Schiff B, Ganly I, Ow T, Cohen E, Genden E, et al. Tracheostomy during SARS-CoV-2 pandemic: recommendations from the New York Head and Neck Society. Head Neck 2020;42(6):1282-1290. DOI: 10.1002/hed.26166.

25. Ahn D, Lee GJ, Choi YS, Park JW, Kim JK, Kim EJ, et al. Timing and clinical outcomes of tracheostomy in patients with COVID-19. Br J Surg 2021;108(1):e27-e28. DOI: 10.1093/bjs/znaa064.

26. Angel L, Kon ZN, Chang SH, Rafeq S, Palasamudram Shekar S, Mitzman $B$, et al. Novel percutaneous tracheostomy for critically ill patients with COVID-19. Ann Thorac Surg 2020;110(3):1006-1011. DOI: 10.1016/ j.athoracsur.2020.04.010.

27. McGrath BA, Brenner MJ, Warrillow SJ, Pandian V, Arora A, Cameron TS, et al. Tracheostomy in the COVID-19 era: global and multidisciplinary guidance. Lancet Respir Med 2020;8(7):717-725. DOI: 10.1016/ S2213-2600(20)30230-7.

28. Sebastian SK, Amar PS, Sharma R, Gupta M, Ramesh S. Tracheostomy in Covid-19 patients: surgical concerns and considerations. Indian J Otolaryngol Head NeckSurg 2021;1-4.DOI: 10.1007/s12070-021-02383-5.
29. Combes A, Luyt CE, Nieszkowska A, Trouillet JL, Gibert C, Chastre J. Is tracheostomy associated with better outcomes for patients requiring long-term mechanical ventilation? Crit Care Med 2007;35(3):802-807.

30. Möhlenkamp S, Thiele H. Ventilation of COVID-19 patients in intensive care units. Herz 2020;45(4):329-331. DOI: 10.1007/s00059-020-04923-1.

31. Wölfel R, Corman VM, Guggemos W, Seilmaier M, Zange S, Müller MA, et al. Virological assessment of hospitalized patients with COVID-2019. Nature 2020;581(7809):465-469. DOI: 10.1038/s41586-020-2196-x [published correction appears in Nature 2020;588(7839):E35].

32. To KK, Tsang OT, Leung WS, Tam AR, Wu TC, Lung DC, et al. Temporal profiles of viral load in posterior oropharyngeal saliva samples and serum antibody responses during infection by SARS-CoV-2: an observational cohort study. Lancet Infect Dis 2020;20(5):565-574. DOI: 10.1016/S1473-3099(20)30196-1.

33. Bullard J, Dust K, Funk D, Strong JE, Alexander D, Garnett $L$, et al. Predicting infectious severe acute respiratory syndrome coronavirus 2 from diagnostic samples. Clin Infect Dis 2020;71(10):2663-2666. DOI: 10.1093/cid/ciaa638. 